\title{
Battery Charging Equipment for Tidal Power Generation System by Darrieus Turbine
}

\author{
Koji Masuda, Keiichi Yoshino* \\ Kitakyushu National College of Technology, 5-20-1 Shii, Kokuraminamiku, Kitakyushu, Fukuoka \\ 802-0985, JAPAN \\ *Corresponding Author: yoshino@kct.ac.jp
}

\begin{abstract}
This paper describes a charging equipment to follow maximum efficiency of the water turbine. It charges a battery with electric power by tidal power generation at Kanmon Straits. The generator is counter-rotating three-phase one and is driven by Darrieus turbine in parallel. The generator output is converted to direct current and the battery is charged. The methods of charging are floating charge and charging current control. We confirmed that floating charge of simple equipment charged $2.7 \mathrm{kWh}$ at a large tidal range period. The charging current control was able to follow the maximum efficiency under more than $0.8 \mathrm{~m} / \mathrm{s}$ current speed.
\end{abstract}

Keywords: tidal current, Darrieus, battery charging equipment, counter-rotating.

\section{Introduction}

In modern society, fossil fuel electric power generation of the current main generation has limitations of fuel. Therefore, the development of new energy alternative to fossil fuel is hurried, and methods of power generation by natural energy have been proposed ${ }^{(1)}$. Although there are solar, wind and wave power generation. Methods of power generation utilizing tidal current have not been put to practical use due to the low energy density.

The tidal current is ocean stream by tidal phenomenon. Moreover, a tidal power generation system converts the energy of tidal flows into electricity with water turbine. Then, the energy is stable source, since tidal current is not affected by weather unlike wind power, and it is disposed to flow at a constant frequency ${ }^{(2)}$. Furthermore, as a density of seawater is more than 800 times greater than that of air, the current velocity of $1 \mathrm{~m} / \mathrm{s}$ corresponds to the wind speed of 9 $\mathrm{m} / \mathrm{s}$ in air because the energy of a fluid is proportional to the density and the cube of the stream velocity. Thus, the tidal power generation is expected as a promising way of utilizing the natural energy ${ }^{(3)}$.

Darrieus type was selected in the water turbine. In addition, the twin-turbine configuration was preferred in the tidal current power generation than the single turbine ${ }^{(3)}$. In this study, counter-rotating generator was used. Each turbine is connected to the rotor and the stator (Shown in Fig. 1), and these rotate in the opposite direction. The following points are expected.

(a) Generating power will be available at low revolution since relative speed is doubled. Therefore, it leads to high efficiency of the generator.

(b) The number of generator is only one because one turbine rotates the rotor, and another rotates the stator. Thus, power generation systems will become compact.

This paper describes a charging equipment to convert tidal power into electric energy.

\section{Tidal Power Generation}

\subsection{Energy Theory}

The fluid kinetic energy per unit time $P$ is given by:

$$
P=\frac{1}{2} \rho A V^{3}
$$

( $\rho$ : fluid density, A : projected area, $V$ : fluid velocity)

The Maximum shaft power of ideal water turbine $P_{\text {tmax }}$ is described by:

$$
P_{\text {tmax }}=\frac{8}{27} \rho A V^{3}
$$




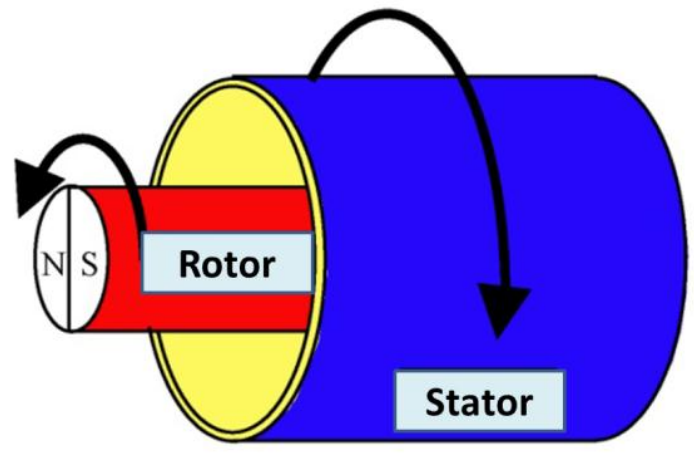

Fig.1. Principle of Counter-Rotating generator.

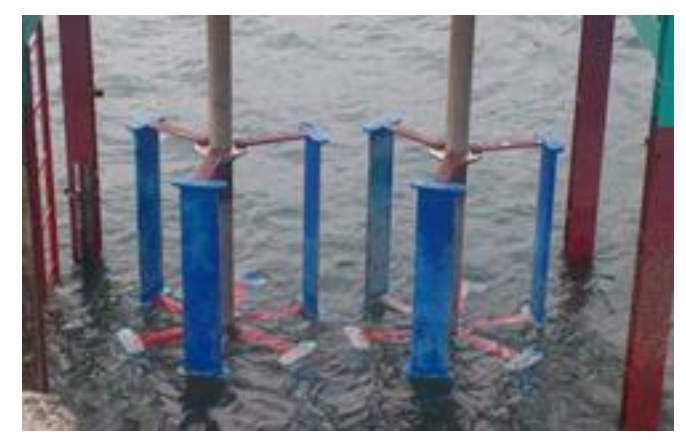

(a) Darrieus water turbine in Kanmon Straits.

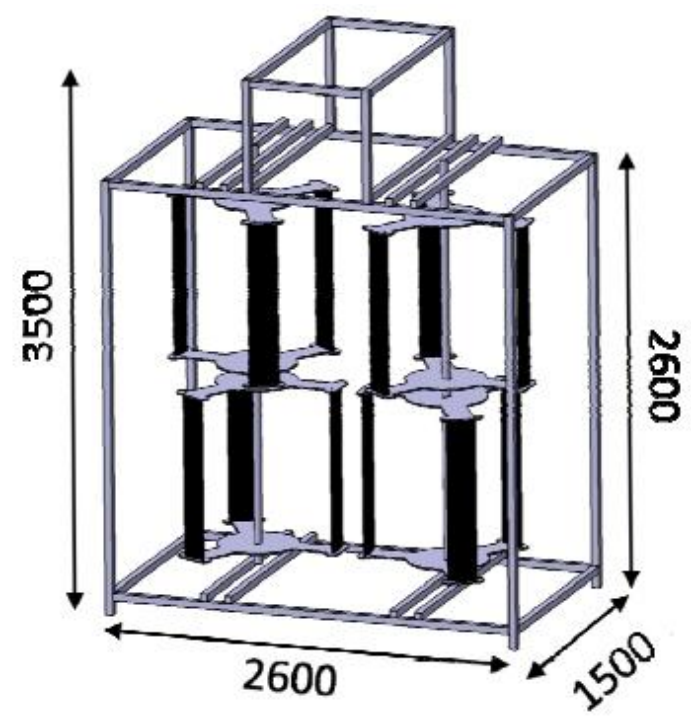

(b) Size of demonstration unit.

Fig.2. Water turbine.
Table 1. Specifications of the generator.

\begin{tabular}{|c|c|}
\hline Rated voltage [V] & 200 \\
\hline Rated current [A] & 13.4 \\
\hline Rated speed [rpm] & 150 \\
\hline Pairs of poles & 16 \\
\hline
\end{tabular}

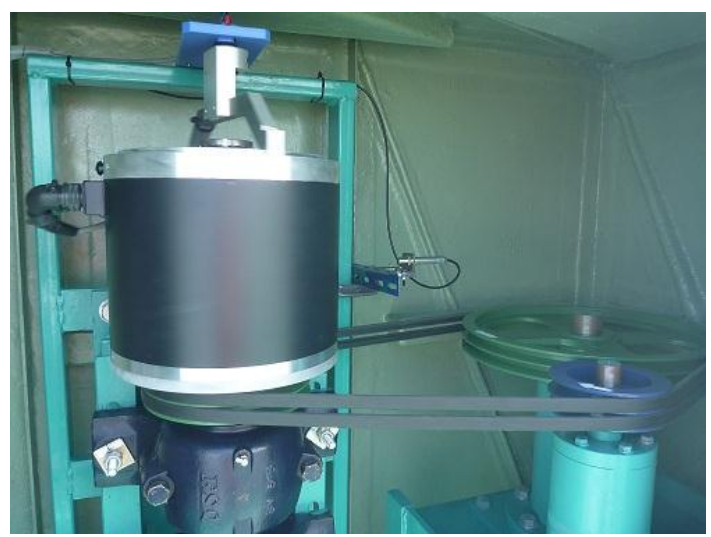

Fig.3. Counter-Rotating generator.

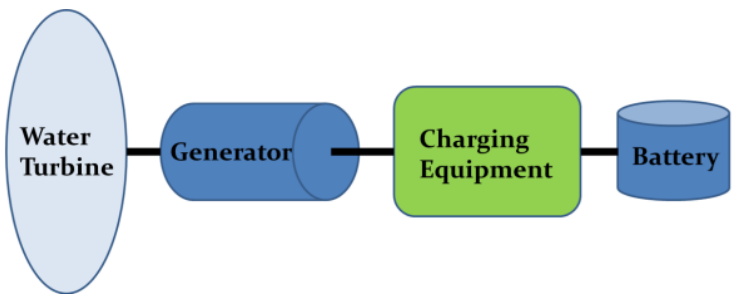

Fig.4. System of tidal power generation.

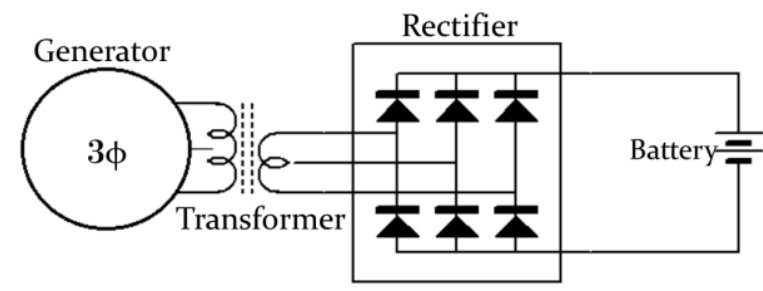

Fig.5. Circuit configuration of floating charge.

From Eq. (1) and Eq. (2), the peak efficiency of the water turbine $\eta_{\text {tmax }}$ is as follows:

$$
\eta_{\text {tmax }}=\frac{P_{\operatorname{tmax}}}{P}=0.593
$$

Actually, this is described as $C_{p}$. Therefore, the shaft power $P_{t}$ is expressed in the following equation:

$$
P_{t}=\frac{1}{2} \rho A V^{3} C_{p}
$$




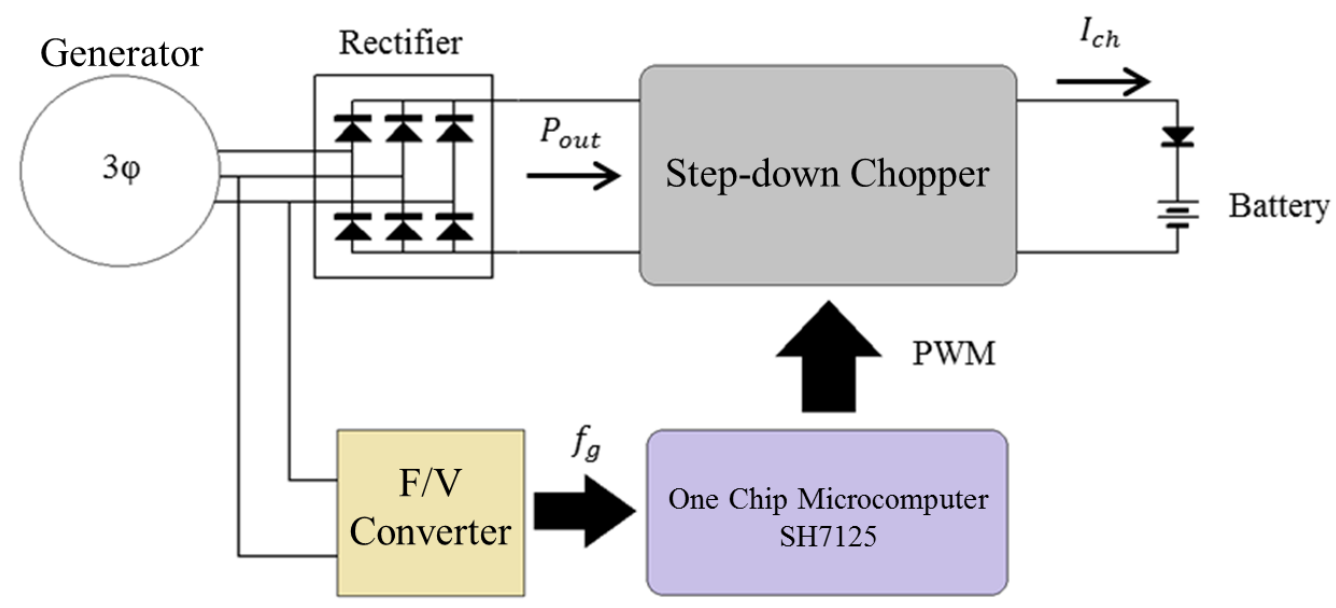

Fig.6. Circuit configuration of charging current control.

\subsection{Darrieus Water Turbine}

In the present study, a Darrieus water turbine was selected in a vertical axis water axis. It has the three straight blades in the rotor as shown in Fig.2a. Regardless of tidal current direction, this turbine is unidirectional rotation. Demonstration unit size is shown in Fig.2b. Each axis turns opposite direction and drives rotor and stator of the generator.

\subsection{Counter-Rotating Generator}

The counter-rotating generator is shown in Fig.3. The stator of the generator normally fixed a base is driven counter direction behind rotor spin. It doubles the relative speed of stator and rotor. This feature has an advantage in slow rotation water turbine. The specifications of the generator are listed in Table 1.

\subsection{System of Tidal Power Generation}

The system outline of tidal power generation is shown in Fig.4. The battery potential is $24 \mathrm{~V}$. Methods of charging are floating charge and charging current control in the charging equipment.

\subsection{Floating Charge}

Fig.5. shows the circuit configuration of floating charge. First, outputs of generator are transformed to fix appropriate voltage. Second, the rectifier converts alternate current into direct current. It has some advantages. In the first place, this system is simple. Next, when the turbine rotates low speed, the output voltage is lower than battery voltage. The rectifiers are off all. Therefore, the charging current is zero. As tidal current speed increases enough to be charge the battery, the voltage exceeds $24 \mathrm{~V}$ and rectifiers are on. The charging current is decided by impedance of generator and rectifier. Since the impedance is generally small, the current increases rapidly to change of voltage.

\subsection{Charging Current Control}

Circuit configuration of charging current control is shown in Fig.6. The direct current power is used for charging by the step-down chopper circuit. The chopper circuit is driven by SuperHitachi 7125 (SH7125) microcomputer as shown in Fig.7. SH7125 received frequency of the generator $f_{g}$ from the frequency/voltage converter ( $\mathrm{F} / \mathrm{V}$ converter). Moreover, the charging current is controlled from $f_{g}$. Also, charging current is measured by current sensor.

The charging flow is as below:

(a) Obtain angular velocity of the generator $\omega_{m}$ $\omega_{m}$ is given by:

$$
\begin{aligned}
\omega_{m} & =2 \pi f_{g} / P \\
& (\mathrm{P}: \text { pairs of poles })
\end{aligned}
$$

(b) Calculate output power $P_{\text {out }}$

Fig.8. is shown the relationship between rotation speed and $P_{\text {out }}$. $P_{\text {out }}$ is proportional to the cube of fluid velocity from Eq. (4), and rotation speed is proportional to fluid velocity. Thus, $P_{\text {out }}$ is also proportional to the cube of $\omega_{m}$. This graph was approximated by cubic curve. The obtained equations are described by: 


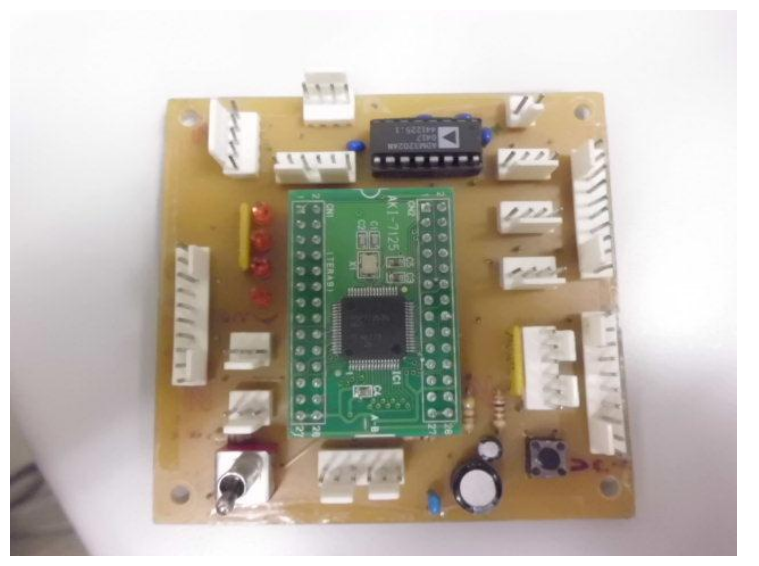

Fig.7. Microcomputer unit SH7125.

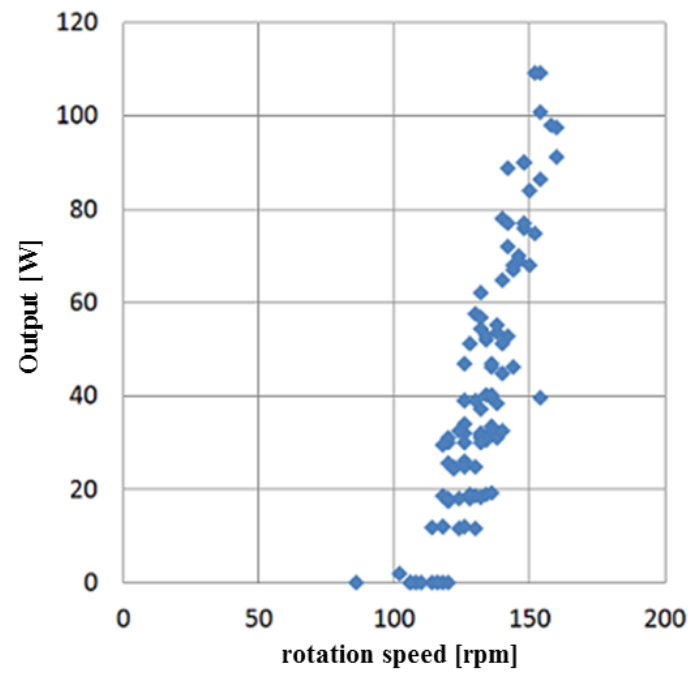

Fig.8. Generated power vs. rotation speed.

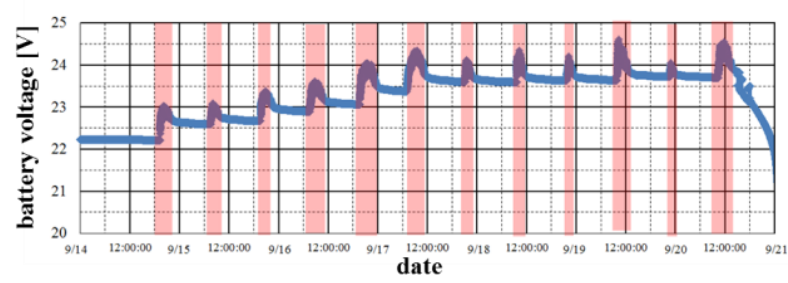

(a) Battery voltage performance in floating charge.

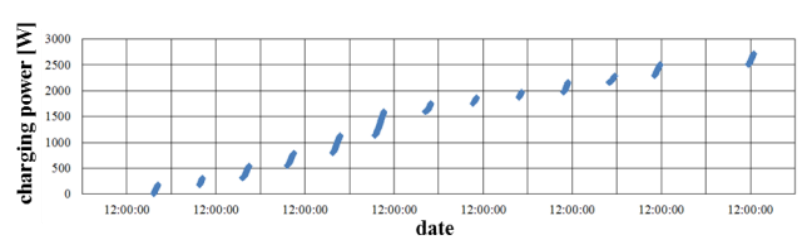

(b) Integrated value of charging power.

Fig.9. Results of floating charge.

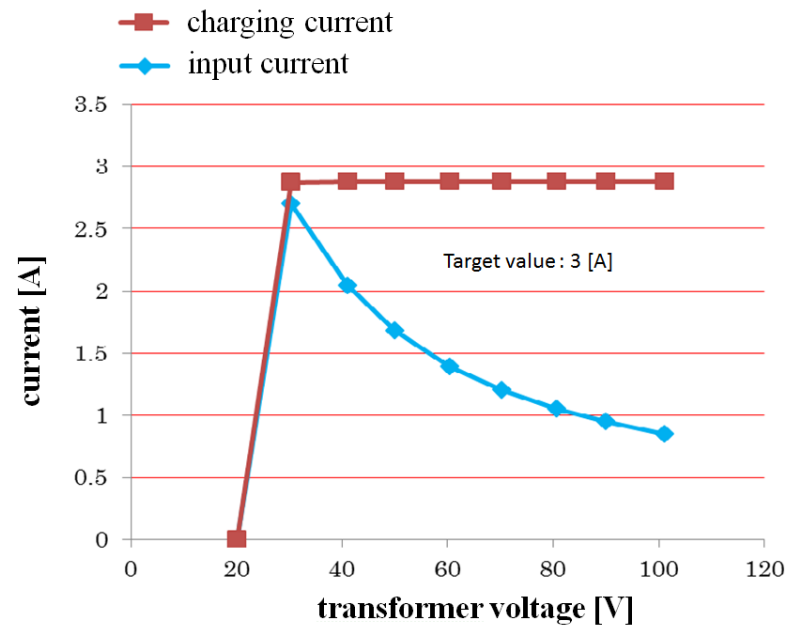

Fig.10. Current control.

$$
\begin{aligned}
& P_{\text {out }}=0.0212 \omega_{m}{ }^{3}-W_{l} \\
& W_{l}=42
\end{aligned}
$$

$\left(W_{l}:\right.$ mechanical and electric loss $\left.[\mathrm{W}]\right)$

(c) Decide on charging current $I_{c h}$

Since $P_{\text {out }}$ is expressed as a product of battery potential $V_{b}$ and $I_{c h}, I_{c h}$ is expressed in the following equation:

$$
I_{c h}=\frac{P_{\text {out }}}{V_{b}}
$$

(d) Control charging current

The $I_{c h}$ obtained from Eq. (8) is targeted value. SH7125 outputs pulse width modulation signal (PWM), and controls the current with proportional control.

\section{Experiment}

\subsection{Floating Charge}

The transformer was adjusted so that the water turbine does not stall. Moreover, the transformer ratio was 100 to 30. Therefore, we tried charging tests in the ratio. This experiment was performed to verify the performance of demonstration unit.

The results of floating charge were shown in Fig. 9. The battery voltage was increased in Fig. 9a. As shown in Fig. $9 \mathrm{~b}$, the charging power was $2.7 \mathrm{kWh}$ at a large tidal range period. 


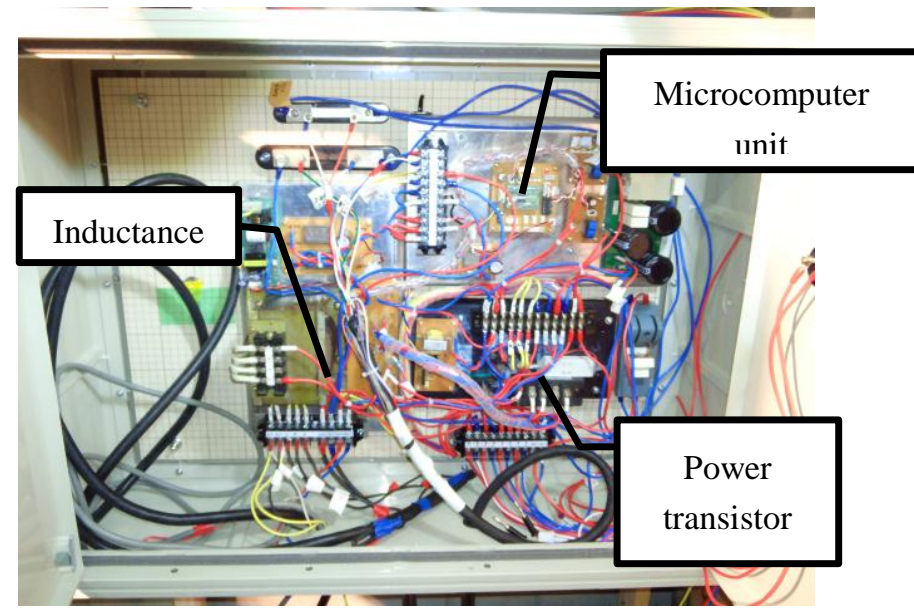

Fig.11. Charging equipment for current control method.

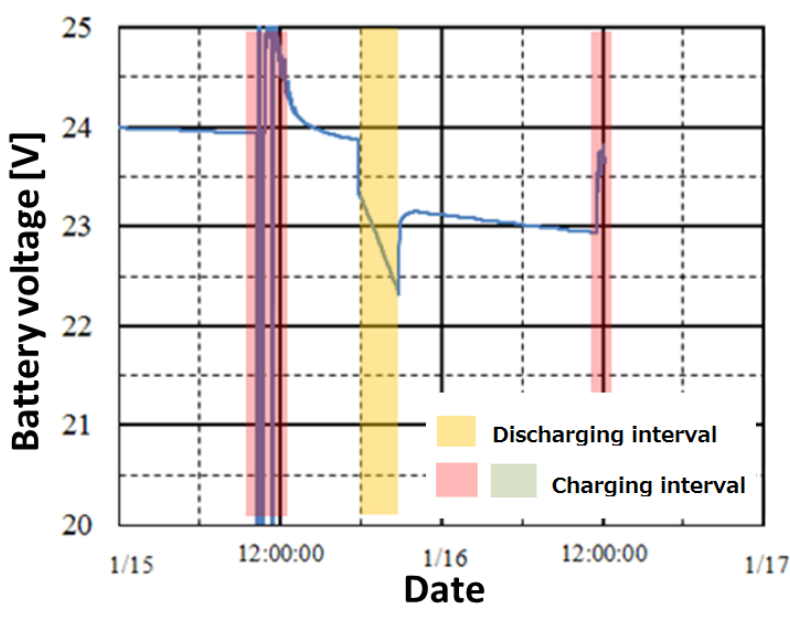

(a) Battery voltage performance.

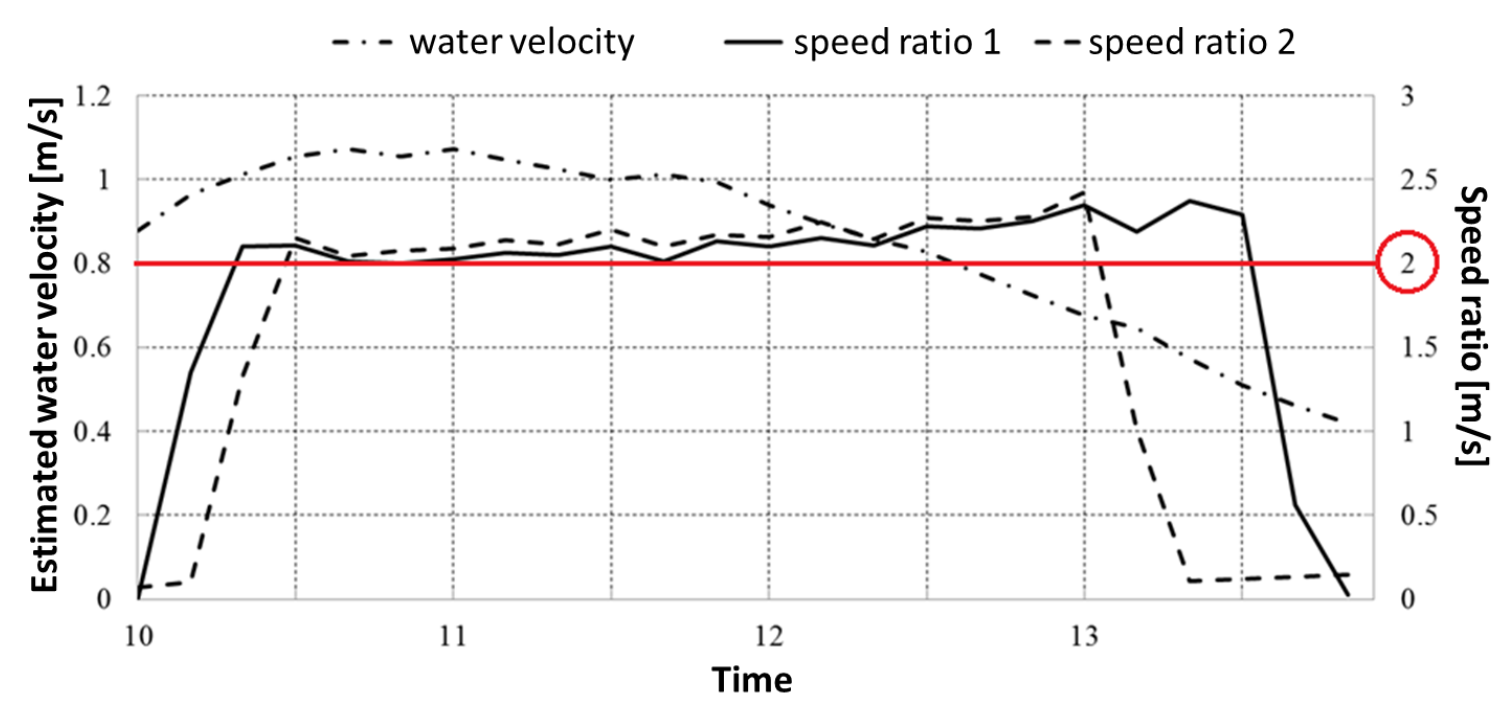

(b) Estimated water velocity and ratio speed.

Fig.12. Results of charging current control.

\subsection{Charging Current Control}

First, we confirmed that the current is controlled constant value as shown in Fig. 10. The single-phase transformer was used instead of the generator. The transformer voltage was varied against arbitrary charging current.

Second, the charging equipment was built as shown in Fig.11. Moreover, it was tested to confirm the charging operation.
The test results were shown in Fig .12. The battery was charged because the voltage increased in Fig .12a. Fig .12b showed the relationship estimated water velocity and speed ratio. The water turbines are maximum efficiency in ratio speed $2 \mathrm{~m} / \mathrm{s}$. More than $0.8 \mathrm{~m} / \mathrm{s}$ water velocity, the speed ratio was located near $2 \mathrm{~m} / \mathrm{s}$. Therefore, the turbines were peak efficiency. However, following the efficiency was inadequacy below $0.8 \mathrm{~m} / \mathrm{s}$ water velocity. 


\section{Conclusion}

In this paper, we described the charging equipment for tidal power. It was shown that the floating charge equipment can charge in simple configuration. Moreover, in demonstration experiment, the battery was charged $2.7 \mathrm{kWh}$ at a large tidal range period. In charging current control, following maximum efficiency was realized under more than $0.8 \mathrm{~m} / \mathrm{s}$ water velocity.

As a near future work, the charging current control equipment should be adjusted so that the water turbines are constantly peak efficiency.

\section{References}

(1) Masayuki Fuji, Shigeo Wataya : "Research on the ocean tide generation in Obatake-Seto", The Bulletin of Institute of National Colleges of Technology, Oshima College of Maritime Technology, Vol. 39, pp. 52-57, 2006 (in japanese)

(2) Seiji Kihoh, Mitsuhiro Shiono : "Electric Power Generations from Tidal Currents by Darrieus Turbine at Kurushima Straits", T. IEE Japan, Vol. 112-D, pp. 530-538, 1992 (in Japanese)

(3) Koju Hiraki, Kohei Nishida, Ryo Wakita, Manabu Takao : "Guide Vanes for Darreus Water Turbine in Tidal Current", International Conference on Renewable Energies and Power Quality, 2013. 